
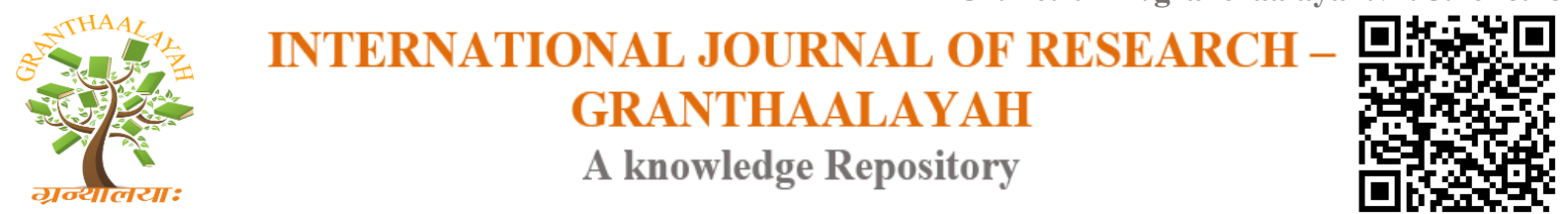

Management

\title{
MICRO FINANCE DEVELOPMENTAL STRATEGIES TO REDUCING POVERTY NUXES: AN OVERVIEW
}

\author{
Dr. Malappa Bheemaraya *1 \\ ${ }^{*}$ Guest Lecturer, Government First Grade College, Chittapur, Kalaburagi Dist, INDIA
}

\begin{abstract}
Microcredit is a financial innovation which originated in developing countries where it has successfully enabled extremely impoverished people to engage in self-employment projects that allow them to generate income, begin to built wealth and exit from poverty. Microfinance is the extension of very small loans to the entrepreneurs and to others living in poverty that are not considered bankable. These peoples lack collateral, steady employment and a verifiable credit history and therefore cannot meet even the most minimal qualifications to gain access to traditional credit. Microcredit is a tool for socioeconomic development. This paper describes different strategies such as demand service and supply side service to reducing the poverty nuxes in India and also tells challenging and achievement of using this strategies to reducing the poverty.
\end{abstract}

Keywords:

Micro finance, Poverty, Strategies, India, Micro Finance Services.

Cite This Article: Dr. Malappa Bheemaraya, "MICRO FINANCE DEVELOPMENTAL STRATEGIES TO REDUCING POVERTY NUXES: AN OVERVIEW” International Journal of Research - Granthaalayah, Vol. 4, No. 5 (2016): 7-18.

\section{INTRODUCTION}

Over 900 million people in about 180 million households in the Region live in poverty. Most of the Region's poor (i.e., those who earn less than $\$ 1.00$ a day) or more than 670 million people, live in rural areas although urban poverty is also a growing problem in virtually all developing countries. Most rural poor people are engaged in agricultural or related activities as laborers or small scale farmers. Many are also involved in a variety of microenterprises. In many countries, women, who are a significant proportion of the poor and suffer disproportionately from poverty, operate many of these microenterprises. Institutional microfinance is defined to include microfinance services provided by both formal and semiformal institutions. Microfinance institutions are defined as institutions whose major business is the provision of microfinance services. 
Since India became part of the global economy and underwent economic reform in 1991, its economy is growing at a faster rate of nearly 10 per cent per annum. In the process, India has become the fourth largest economy in the world. In the last two decades, a significant proportion of the population across the country has reaped the benefits of this economic growth. They have become the part of global economy and market, and their lives have transformed into one of global citizens with all the comforts and luxury in life. Apart from this burgeoning middle class in the country, the economic growth seemed to have touched the lives of the poor also. According to the National Sample Survey results, people living below poverty line have dramatically come down during the post economic reform era. People living below poverty line (BPL) came down from 36 per cent in 1993-1994 (50th Round, NSSO) to 26 per cent in 19992000 (55th Round, NSSO). Many economists question this dramatic change in poverty level. However, the intention of this paper is not to join the debate on the level of poverty reduction in the country but to recognize the reduction

\section{DEFINITION OF MICROFINANCE}

Microfinance is the provision of a broad range of financial services such as deposits, loans, payment services, money transfers, and insurance to poor and low-income households and, their microenterprises. Microfinance services are provided by three types of sources :(i)formal institutions, such as rural banks and cooperatives;(ii)semiformal institutions, such as nongovernment organizations; and informal sources such as money lenders and shopkeepers.

\section{STRATEGIES DIMENSIONS}

Most formal financial institutions do not serve the poor because of perceived high risks, high costs involved in small transactions, perceived low relative profitability, and inability of the poor to provide the physical collateral usually required by such institutions. The business culture of these institutions is also not geared to serve poor and low-income households. Lacking access to institutional sources of finance, most poor and low-income households continue to rely on meager self-finance or informal sources of microfinance. However, these sources limit their ability to actively participate in and benefit from the development process (figure 2 ). Thus, a segment of the poor population that has viable investment opportunities persists in poverty for lack of access to credit at reasonable costs. The poor also lack access to institutional credit for consumption smoothening and to other services such as payments, money transfers, and insurance. The interest in microfinance has burgeoned during the last two decades: multilateral lending agencies, bilateral donor agencies, developing and developed country governments, and nongovernment organizations (NGOs) all support the development of microfinance. A variety of private banking institutions has also joined this group in recent years. As a result, microfinance services have grown rapidly during the last decade, although from an initial low level, and have come to the forefront of development discussions concerning poverty reduction.

Despite this growth, as concluded in the recently completed Rural Asia Study, "rural financial markets in Asia are ill-prepared for the twenty-first century." About 95 percent of some 180 million poor households in the Asian and Pacific Region (the Region) still have little access to institutional financial services. Development practitioners, policy makers, and multilateral and 
bilateral lenders, however, recognize that providing efficient microfinance services for this segment of the population is important for a variety of reasons.

Microfinance can be a critical element of an effective poverty reduction strategy. Improved access and efficient provision of savings, credit, and insurance facilities in particular can enable the poor to smoothen their consumption, manage their risks better, build their assets gradually, develop their microenterprises, enhance their income earning capacity, and enjoy an improved quality of life (figure1). Microfinance services can also contribute to the improvement of resource allocation, promotion of markets, and adoption of better technology; thus, microfinance helps to promote economic growth and development.

i. Without permanent access to institutional microfinance, most poor households continue to rely on meager self-finance or informal sources of microfinance, which limits their ability to actively participate in and benefit from the development opportunities.

ii. Microfinance can provide an effective way to assist and empower poor women, who make up a significant proportion of the poor and suffer disproportionately from poverty.

iii. Microfinance can contribute to the development of the overall financial system through integration of financial markets. enhance their income earning capacity, and enjoy an improved quality of life (figure 2) Microfinance services can also contribute to the improvement of resource allocation, promotion of markets, and adoption of better technology; thus, microfinance helps to promote economic growth and development.

iv. Without permanent access to institutional microfinance, most poor households continue to rely on meager self-finance or informal sources of microfinance, which limits their ability to actively participate in and benefit from the development opportunities.

v. Microfinance can provide an effective way to assist and empower poor women, who make up a significant proportion of the poor and suffer disproportionately from poverty.

vi. Microfinance can contribute to the development of the overall financial system through integration of financial markets. 


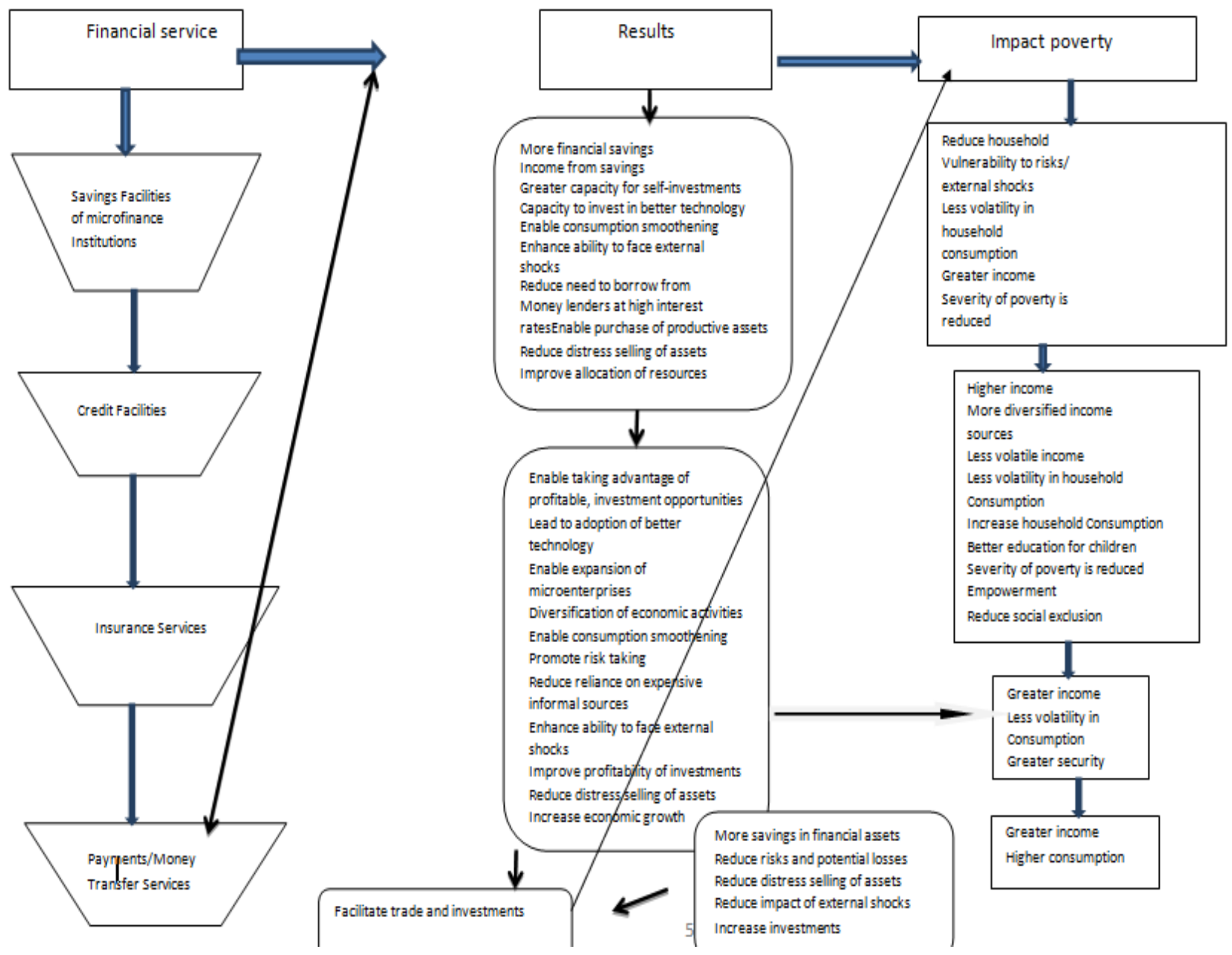

Figure 1: Microfinance poverty reduction nexus chart 


\section{i. Demand service strategies}

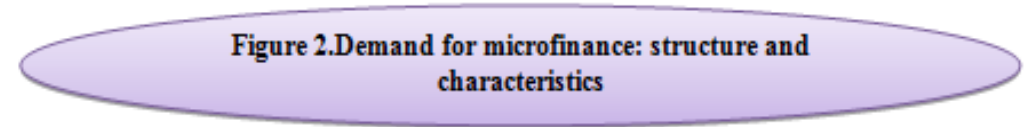

Demand for microfinance: structure and characteristics

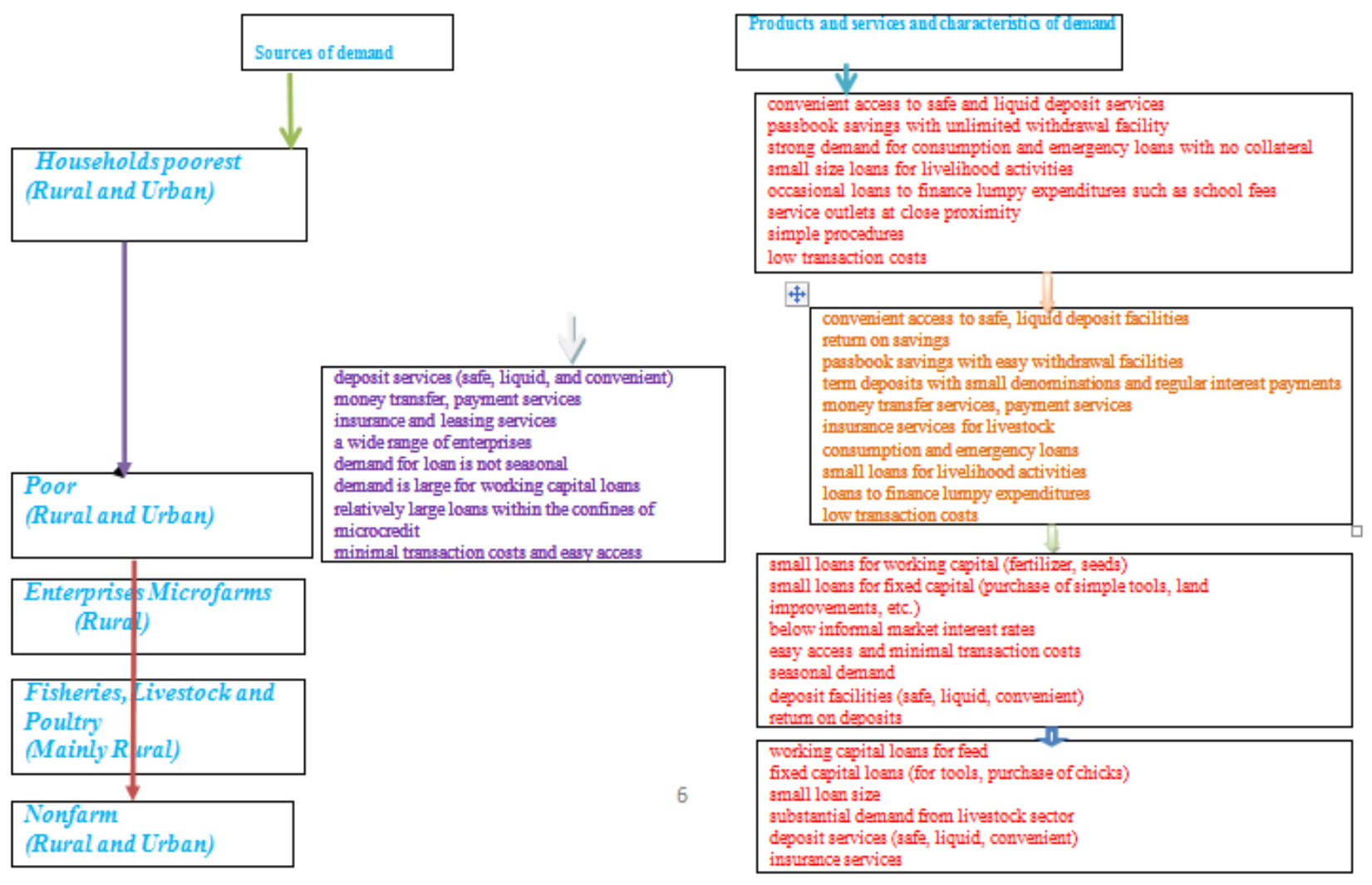




\section{ii. Supply of microfinance services strategies}

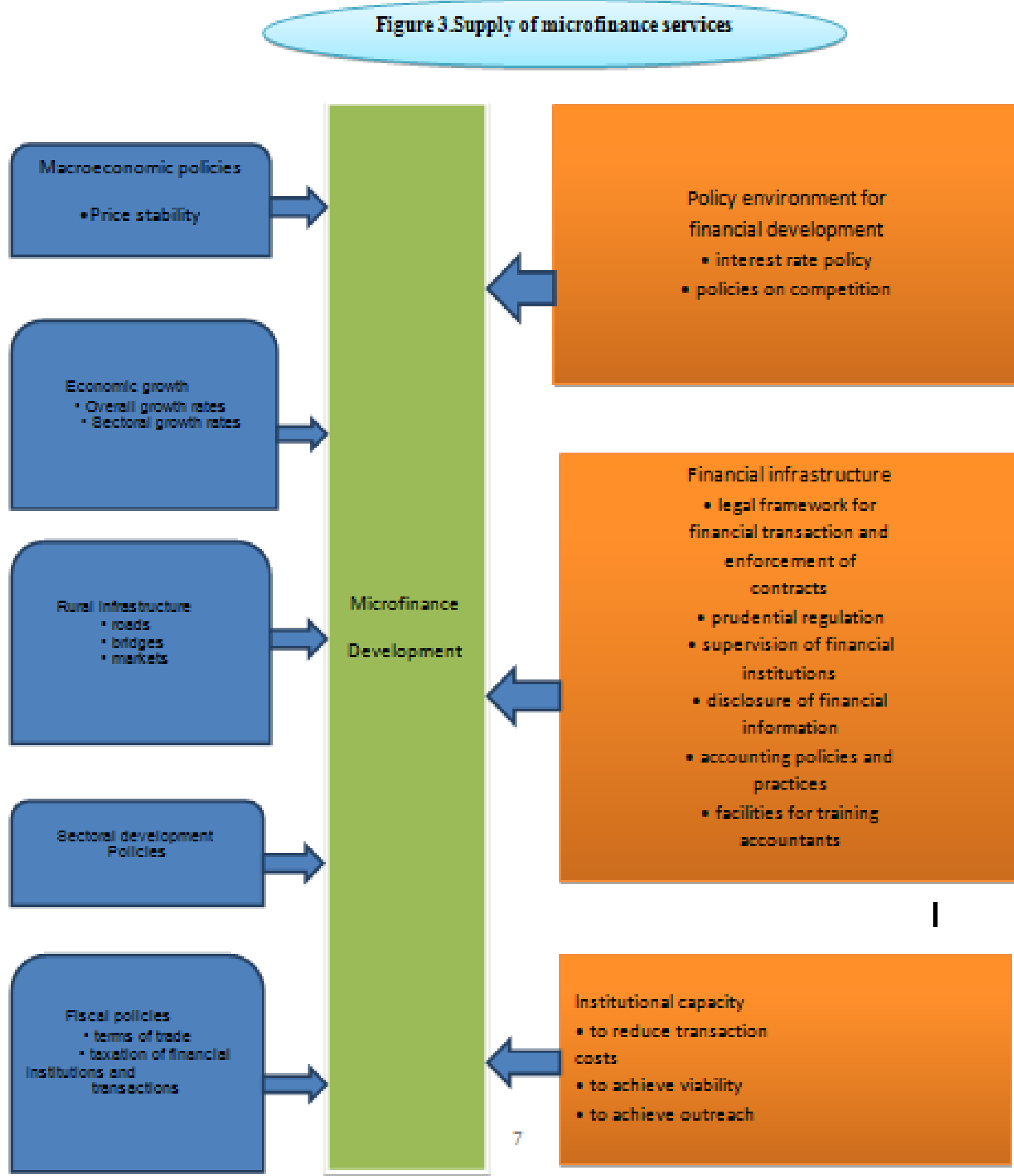


The lack of financial services to the poor is sometimes seen as market failures for credit, insurance, land and human capital, that result in underinvestment by the poor, overinvestment by the rich, and a less efficiency economy (The Economist, 2005).Most formal financial institutions do not serve the poor because of perceived high risks, high costs involved in small transactions, perceived low relative profitability, and inability of the poor to de the physical collateral usually required by such institutions. The business culture of these institutions is also not geared to serve poor and low-income households. Lacking access to institutional sources of finance, most poor and low-income households continue to rely on meager self-finance or informal sources of microfinance. However, these sources limit their ability to actively participate in and benefit from the development process (figure 2). Thus, a segment of the poor population that has viable investment opportunities persists in poverty for lack of access to credit at reasonable costs. The poor also lack access to institutional credit for consumption smoothening and to other services such as payments, money transfers, and insurance. Most of the poor households also find it difficult to accumulate financial savings without easy access to safe institutions that provide deposit services.

\section{i. DEMAND FOR MICROFINANCE SERVICES}

Thepoor and low-income households and their microenterprises in the Region are a diverse group. Their demand for microfinance services also reflects this diversity (figure 3). The collective demand of these groups for financial services is large and the types of services they demand vary across households and microenterprises and over time. This large demand and the heterogeneity of services needed across households and microenterprises and over time have created scope for commercial financial intermediation. Poor and low-income households and their microenterprises in the Region have a large demand for safe and convenient deposit services. This demand reflects the importance of savings for these households and microenterprises for a variety of reasons. The poor need to save for emergencies, investment, consumption, social obligations, education of their children and many other purposes. They have the capacity and willingness to save. Savings are important for microenterprises and provide them with a major source of investment funds. The large demand for deposit services among the poor is confirmed by empirical evidence. For example, the number of savings accounts in unit desas of BRI increased, from 5.0 million in 1988 to 16.1 million in 1996. Most of these accounts belong to poor households. The cooperative rural banks in India had 4.7 million deposit accounts at the end of 1998; while the Association for Social Advancement, microfinance NGO in India, had over 1.4 million active savings accounts of poor households at the end of 1999. Extensive use of informal savings arrangements by poor households is another indicator of their demand for savings facilities. In some countries, the poor pay high prices to those providing deposit services. The demand for deposit services is particularly strong among poor women in the Region. The demand for microcredit that originates both from households and microenterprises is also large. Poor households in the Region require microcredit to finance livelihood activities, for consumption smoothening, and to finance some lumpy nonfood expenses for purposes such as education (e.g., school fees and books), housing improvements, and migration. Many Asian countries have numerous small farms and their operators also require microfinance services. The other source of demand is nonfarm microenterprises, which cover a wide array of activities such as food preparation and processing, weaving, pottery, mat and basket making, furniture making, and pettytrading. 
The demand for other financial services among poor and lowincome households and their microenterprises could also be significant. A good share of rural households borrow, many more save, but all seek to insure against the vagaries of life and therefore the demand for insurance services among the poor is vast.11 A private insurance company in Bangladesh that started to provide micro-insurance services to low-income households on a commercial basis, for example, found that its client base was expanding rapidly. At the end of 1999, this company had over 800,000 clients, about 50,000 of which are considered poor. This experience shows that the supply of such services creates its own demand because the real demand for such services remains hidden when suitable products are not available in the market. Supply of microfinance services The market structure in microfinance varies significantly acrosscountries in the Region depending on their stage of financialdevelopment, level of economic development, policy environment, and other factors (figure 3). However, aspects of the supply, particularly about different types of suppliers, may be usefully discussed. The demand cannot, however, be quantified because the purposes and the time period for which households demand credit is diverse and complex and the demand for credit for different purposes varies with the price and over time. That there are over 180 million poorhouseholds in the Region, however, indicates that the demand could be large.Zeller, M. and M. Sharma (2000).

\section{ii. SUPPLY OF MICROFINANCE SERVICES}

The market structure in microfinance varies significantly acrosscountries in the Region depending on their stage of financial development, level of economic development, policy environment, and other factors (figure 2). However, aspects of the supply, particularly about different types of suppliers, may be usefully discussed.

The microfinance services are supplied mainly by informal sources. Their collective outreach, both breadth and depth, is vast in most countries. They supply mainly short-term credit and charge higher interest rates than semiformal and formal sources. Because of the relatively greater bargaining power enjoyed by the informal suppliers in general, the terms and conditions under which services are provided do not enable the clients to fully harness economic opportunities. The informal sources operate in highly localized areas. Therefore, their contribution to financial intermediation and improvement of resource allocation is also limited. For example, informal sources do not allow savings to be collected from more than a small group of individuals well known to one another, and they do not move funds over large distances. Most informal insurance mechanisms are typically weak, particularly against repeated shocks, and often provide only inadequate protection to poor households.

The involvement of formal sources in microfinance has increased during the last two decades. This greater involvement has stemmed from (i) the expansion of the scope of formal institutions into microfinance through downscaling and establishment of linkage programs with semiformal sources of different types; (ii) the emergence of new formal institutions focused on microfinance, (iii) reforms of state-owned financial institutions such as unit desas of BRI; and (iv) the introduction of new microfinance programs by the governments through nonfinancial institutions. However, the formal operations concentrate mostly on providing credit facilities, and savings mobilization has yet to receive adequate attention, with few exceptions. 


\section{MAJOR ACHIEVEMENT IN MICRO FINANCE}

The MFIs and other financial institutions (OFIs) providing micro finance services have expanded their outreach from a few thousand clients in the 1970s to over 10 million in the late 1990s. The developments in microfinance in the Region have set in motion a process of change from an activity that was entirely subsidy dependent to one that can be a viable business.

i. MFIs and OFIs mobilizing voluntary savings have shattered the myth that poor households cannot and do not save, and proved that savings can be successfully mobilized from poor households. This is perhaps a more important achievement of microfinance in the Region than the expanded outreach in access to credit.

ii. MFIs, OFIs, and their clients have shown that the poor are creditworthy (poor women, in particular) and financial services can be provided to and accessed by the poor on a profitable basis at low transaction costs without relying on physical collateral, if it is done with appropriate financial technology and a commitment to achieve efficiency.

iii. Microfinance services have triggered a process toward broadening and deepening of rural financial markets.

iv. Microfinance services have strengthened the social and human capital of the poor, particularly women, at the household, enterprise, and community level.

v. Sustainable delivery of microfinance services on a large scale in some countries has generated positive developments in microfinance policies and practices among all stakeholders:

vi. Governments, central banks, microfinance service providers, and external funding agencies.

\section{MAJOR CHALLENGES}

\section{CHALLENGING ECONOMIC EMPOWERMENT}

This Study which consider income levels find that for the majority of borrowers income increases are small, and in some cases negative. All the evidence suggests that most women invest in existing activities which are low profit and insecure and/or in their husband's activities. In many type programmes and contexts it is only in a minority of cases that women can develop lucrative activities of their own through credit and savings alone.

It is clear that women's choices about activity and their ability to increase incomes are seriously constrained by gender inequalities in access to other resources for investment, responsibility for household subsistence expenditure, lack of time because of unpaid domestic work and low levels of mobility, constraints on sexuality and sexual violence which limit access to markets in many cultures.

These gender constraints are in addition to market constraints on expansion of the informal sector and resource and skill constraints on the ability of poor men as well as women to move up from survival activities to expanding businesses. There are signs, particularly in some urban markets like Harare and Lusaka, that the rapid expansion of micro-finance programmes may be contributing to market saturation in 'female' activities and hence declining profits. 


\section{CHALLERANGING WELL BEING AND INTO HOUSEHOLD RELATION}

There have undoubtedly been women whose status in the household has improved, particularly where they have become successful entrepreneurs. Even where income impacts have been small, or men have used the loan, the fact that micro-finance programmes have thought women worth targeting and women bring an asset into the household may give some women more negotiating power.

Savings provide women with a means of building up an asset base. Women themselves also often value the opportunity to be seen to be making a greater contribution to household wellbeing giving them greater confidence and sense of self-worth.

However women's contribution to increased income going into households does not ensure that women necessarily benefit or that there is any challenge to gender inequalities within the household. Women's expenditure patterns may replicate rather than counter gender inequalities and continue to disadvantage girls. Without substitute care for small children, the elderly and disabled, and provision of services to reduce domestic work many programmes reported adverse effects of women's outside work on children and the elderly. Daughters in particular may be withdrawn from school to assist their mothers.

Although in some contexts women may be seeking to increase their influence within joint decision-making processes rather than independent control over income (Kabeer 1998), neither of these outcomes can be assumed. Women's perceptions of value and self-worth are not necessarily translated into actual well-being benefits or change in gender relations in the household (Sen 1990, Kandiyoti 1999). Worryingly, in response to women's increased (but still low) incomes evidence indicates that men may be withdrawing more of their own contribution for their own luxury expenditure. Men are often very enthusiastic about women's credit programmes, and other income generation out programmes, for this reason because their wives no longer 'nag' them for money (Mayoux 1999).

Small increases in access to income and influence may therefore be at the cost of heavier work loads, increased stress and women's health. Although in many cases women's increased contribution to household well-being has improved domestic relations, in other cases it intensifies tensions.

\section{CHALLENGING SOCIAL AND POLITICAL ENVIRONMENT}

There have been positive changes in household and community perceptions of women's productive role, as well as changes at the individual level. In societies like Sudan and Bangladesh where women's role has been very circumscribed and women previously had little opportunity to meet women outside their immediate family there have sometimes been significant changes. It is likely that changes at the individual, household and community levels are interlinked and that individual women who gain respect in their households then act as role models for others leading to a wider process of change in community perceptions and male willingness to accept change (Lakshman, 1996). 
Micro-finance has also been strategically used by some NGOs as an entry point for wider social and political mobilisation of women around gender issues. For example SEWA in India, CODEC in Bangladesh and CIPCRE in Cameroon, indicate the potential of micro-finance to form a basis for organization against other issues like domestic violence, male alcohol abuse and dowry.

However there is no necessary link between women's individual economic empowerment and/or participation in micro-finance groups and social and political empowerment. These changes are not an automatic consequence of microfinance per se. As noted above, women's increased productive role has also often had it costs.there is no necessary link between women's individual economic empowerment and/or participation in micro-finance groups and social and political empowerment. These changes are not an automatic consequence of microfinance per se. As noted above, women's increased productive role has also often had it costs. In most programmes there is little attempt to link micro-finance with wider social and political activity. In the absence of specific measures to encourage this there is little evidence of any significant contribution of micro-finance. Micro-finance groups may put severe strains on women's existing networks if repayment becomes a problem (Noponen 1990; Rahman 1999). There is evidence to the contrary that micro-finance and income-earning may take women away from other social and political activities. The evidence therefore indicates that contributions of micro-finance per se to women's empowerment cannot be assumed and current complacency in this regard is misplaced. In many cases contextual constraints at all levels have prevented women from accessing programmes, increasing or controlling incomes or challenging subordination. Where women are not able to significantly increase incomes under their control or negotiate changes in intra-household and community gender inequalities, women may become dependent on loans to continue in very lowpaid occupations with heavier workloads and enjoying little benefit. For some women microfinance has been positively disempowering, as indicated by some of the cases shown above which are far from isolated examples: Credit (i.e. debt) may lead to severe impoverishment, abandonment and put serious strains on networks with other women. Pressure to save may mean women forgoing their own necessary consumption.

The contribution of micro-finance alone appears to be most limited for the poorest and most disadvantaged women. All the evidence suggests the poorest women are the most likely to be explicitly excluded by programmes and also peer groups where repayment is the prime consideration and/or where the main emphasis of programmes is on existing microentrepreneurs. It also suggests that even where they get access to credit they are particularly vulnerable to falling further into debt.

\section{CONCLUSIONS}

These two strategies reducing poverty gaps through all over the world. All said and done, Microfinance remains a powerful tool for development. It may be adrop in the ocean, burette it has made people self-sufficient. Our tasks are to spread Microfinance and bring down the cost of capital and the operating costs and strengthen the bonding between Microfinance and the Formal Financial System. However, for sustainable development of the poor and rural economy, we have to focus on development of rural infrastructure and the rural economy, otherwise there will be few activities requiring finance. 


\section{REFERENCE}

[1] The Economist, 2005, The Hidden Wealth Of The Poor, The Economist, 3 November.

[2] Yaron, J., Benjamin, M., \& Piprek, G. (1997) Rural Finance.Issues, Design, and Best Practices, World Bank, Washington D.C.

[3] Hulme, D., \& Mosley, P. (1996) Finance Against Poverty, Routledge, London.

[4] Meyer, R.L., \&Nagarajan, G. (1999) Rural Financial Markets in Asia: Policies. Paradigms, and Performance, Oxford University Press.

[5] Bank for International Settlements: Secretariat of the Basle Committee on Banking Supervision (January 2001) "The New Basle Accord: An Explanatory Note".

[6] PriyaBasu, PradeepSrivastava (2005) Exploring Possibilities Microfinance and Rural Credit Access for thePoor in India, Economic and Political Weekly, Vol. 40 No. 17 April 23 - April 29, 2005.

[7] Rajaram Das Guptha, (2001), an Informal Journey through SHGs, Indian Journal of Agricultural Economics, Vol. 56, No 3, July-Sep 2001.

[8] Rajshekar D. (2004), Micro Finance, Poverty, and Empowerment of Women: A case study of two NGOs fromAndhra Pradesh and Karnataka, ISEC publications, Bangalore, 2004.

[9] Fisher, Thomas and M.S. Sriram ed., 2002, Beyond Micro-credit: Putting Development Back into Microfinance, New Delhi: Vistaar Publications; Oxford: Oxfam.

[10] Kabeer $N$ (2001), "Conflicts Over Credit: Re-evaluation the Empowerment Potential of Loans to Women in Rural Bangladesh”: World Development,Vol.29,No.1.

[11] Mayoux, L. 1998a. Women's Empowerment and Micro-finance programmes: Approaches, Evidence and Ways Forward. The Open University Working Paper No 41. 